\title{
Sequence-Independent DNA Adsorption on Few-Layered Oxygen-Functionalized Graphene Electrodes: An Electrochemical Study for Biosensing Application
}

\author{
Narges Asefifeyzabadi ${ }^{1}$, Torrey E. Holland ${ }^{2} \mathbb{D}$, Poopalasingam Sivakumar ${ }^{2}\left(\mathbb{D}\right.$, Saikat Talapatra ${ }^{2}$, \\ Ishani M. Senanayake ${ }^{1}$, Boyd M. Goodson ${ }^{1}$ and Mohtashim H. Shamsi ${ }^{1, *(D)}$ \\ 1 School of Chemical and Biomolecular Sciences, Southern Illinois University, 1245 Lincoln Drive, \\ Carbondale, IL 62918, USA; narges.asefifeyzabadi@siu.edu (N.A.); ishani.senanayake@siu.edu (I.M.S.); \\ bgoodson@chem.siu.edu (B.M.G.) \\ 2 School of Physics and Applied Physics, Southern Illinois University, Carbondale, IL 62918, USA; \\ torrey.holland@siu.edu (T.E.H.); psivakumar@siu.edu (P.S.); saikat@siu.edu (S.T.) \\ * Correspondence: mshamsi@siu.edu
}

check for updates

Citation: Asefifeyzabadi, N.; Holland, T.E.; Sivakumar, P.; Talapatra, S.; Senanayake, I.M.; Goodson, B.M.; Shamsi, M.H. Sequence-Independent DNA Adsorption on Few-Layered Oxygen-Functionalized Graphene Electrodes: An Electrochemical Study for Biosensing Application. Biosensors 2021, 11, 273. https://doi.org/ 10.3390/bios11080273

Received: 26 July 2021

Accepted: 12 August 2021

Published: 14 August 2021

Publisher's Note: MDPI stays neutral with regard to jurisdictional claims in published maps and institutional affiliations.

Copyright: (c) 2021 by the authors. Licensee MDPI, Basel, Switzerland. This article is an open access article distributed under the terms and conditions of the Creative Commons Attribution (CC BY) license (https:/ / creativecommons.org/licenses/by/ $4.0 /)$.

\begin{abstract}
DNA is strongly adsorbed on oxidized graphene surfaces in the presence of divalent cations. Here, we studied the effect of DNA adsorption on electrochemical charge transfer at few-layered, oxygen-functionalized graphene $\left(\mathrm{GO}_{\mathrm{x}}\right)$ electrodes. DNA adsorption on the inkjet-printed $\mathrm{GO}_{\mathrm{x}}$ electrodes caused amplified current response from ferro/ferricyanide redox probe at concentration range $1 \mathrm{aM}-10 \mathrm{nM}$ in differential pulse voltammetry. We studied a number of variables that may affect the current response of the interface: sequence type, conformation, concentration, length, and ionic strength. Later, we showed a proof-of-concept DNA biosensing application, which is free from chemical immobilization of the probe and sensitive at attomolar concentration regime. We propose that $\mathrm{GO}_{\mathrm{x}}$ electrodes promise a low-cost solution to fabricate a highly sensitive platform for label-free and chemisorption-free DNA biosensing.
\end{abstract}

Keywords: DNA biosensors; graphene electrodes; inkjet-printing; trinucleotide repeats; label-free; electrochemical biosensors

\section{Introduction}

Graphene comprises a single layer of graphite in which carbon atoms arrange themselves in a 2D hexagonal lattice with metal-like charge carrier properties [1,2]. The interfacial properties of graphene interface, e.g., charge transport, can be easily and sensitively modulated by interactions with biomolecules [3-5], Therefore, single and multilayered graphene and its derivatives (i.e., graphene oxide and reduced graphene) have been widely exploited as sensing platforms to detect DNA [6-8], proteins [9-12], and small molecules [13] using a variety of detection methods including optical $[6,13]$, scanning probe [10], electrical [7,8], and electrochemical techniques $[9,11,12]$.

To harness the properties of such interfaces for sensitive biosensing platforms, interactions of nucleic acids with graphene-based surfaces have been extensively studied in two regimes, i.e., physisorption and chemisorption [14]. The interfacing of DNA and graphene surfaces is often achieved by the simple mixing of DNA oligonucleotide solution with graphene solution (a liquid/liquid interface) to form DNA-graphene hybrids [15,16], and DNA self-assembly on graphene electrodes (a liquid/solid interface) [17]. Theoretical studies have confirmed $\pi$ stacking interactions between hydrophobic DNA basepairs and graphitic carbon rings of graphene as a driving force of adsorption [18-20]. Nucleobases show differential interactions where base rings are parallel to the graphene surface, which maximizes $\pi-\pi$ stacking [21]. Theoretical studies have ranked the adsorption energies of bases on graphene as $\mathrm{G}>\mathrm{A}>\mathrm{T}>\mathrm{C}[18,19]$, whereas experimental studies involving isothermal titration calorimetry indicates that the trend follows as $\mathrm{G}>\mathrm{A}>\mathrm{C}>\mathrm{T}$ [22]. 
Thus, non-electrostatic interactions dominate the binding, where purine bases bind more strongly than pyrimidines $[18,22,23]$. Moreover, not all bases in a duplex conformation are adsorbed, and a diverse range of DNA conformations are likely to exist, which may result in competitive binding between bases and graphene oxide (GO)-leading to partial denaturation of double-stranded DNA (dsDNA) and exposition of single-stranded DNA (ssDNA) regions [24]. Both DNA and GO carry negative charge; therefore, a high ionic strength (up to a few $\mathrm{mM} \mathrm{Mg}^{2+}$ or $\geq 100 \mathrm{mM} \mathrm{NaCl}$ ) is used to facilitate the adsorption that overcomes the kinetic barrier [15]. DNA conformation can also influence the adsorption process due to intramolecular basepairing. A solution-based study involving the adsorption of ssDNA on GO has revealed that shorter DNA adsorbs faster and tighter to the surface, whereas lower $\mathrm{pH}$ and higher ionic strength conditions favor the adsorption. Despite the expanded theoretical and experimental research in this area, the question of how DNA interaction with graphene-based materials such as oxidized graphene surfaces can modulate electrical and electrochemical charge transport across the interface-a liquid/solid interface-is underexplored.

For this study, we hypothesized that DNA adsorption on oxidized graphene interface may lead to unique electrochemical signatures, which eventually may lead to development of a simple electrochemical DNA biosensor. First, we prepared and thoroughly characterized a few-layered, oxygen-functionalized graphene ink $\left(\mathrm{GO}_{\mathrm{x}}\right)$, followed by fabricating the $\mathrm{GO}_{\mathrm{x}}$ electrodes on indium tin oxide (ITO) surfaces by inkjet printing, as illustrated in Scheme 1a. Then, we physisorbed the DNA sequences on the $\mathrm{GO}_{\mathrm{x}}$ electrodes in high divalent cation concentration $\left(20 \mathrm{mM} \mathrm{Mg}^{2+}\right)$, and monitored the electrochemical responses of the interface using differential pulse voltammetry, as depicted in Scheme 1b. The proposed sensing mechanism in the scheme explains the lower current obtained on the unmodified electrode due to repulsion between the negatively charged redox probe and negative O-groups on the $\mathrm{GO}_{x}$ surface. Then, the adsorption of the DNA sequence on a $\mathrm{GO}_{\mathrm{x}}$ surface in presence of $\mathrm{Mg}^{2+}$ ions reduces the electrostatic repulsion, which leads to higher diffusion of the redox probe producing higher electrochemical current measured by DPV. In particular, we studied their electrochemical signature with respect to sequence type, conformation, concentration, length, and ionic strength in the presence of a soluble redox probe, $\mathrm{Fe}(\mathrm{CN})_{6}{ }^{3-/ 4-}$. Finally, we performed a proof-of-concept biosensing test that does not require chemical labelling and immobilization of the probe.

a)
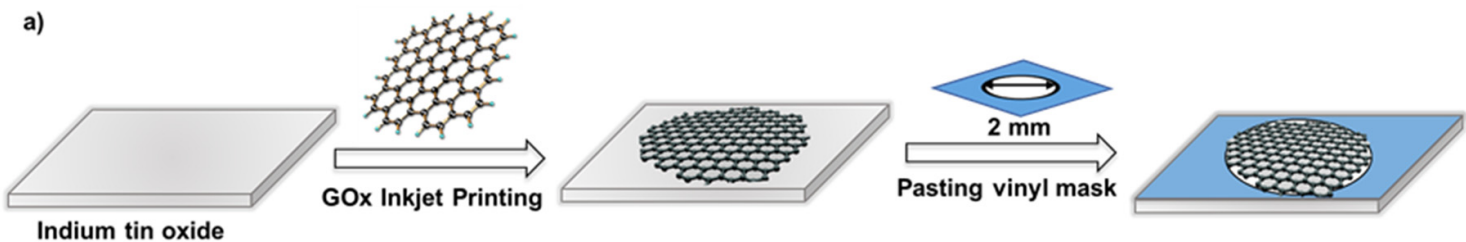

b)
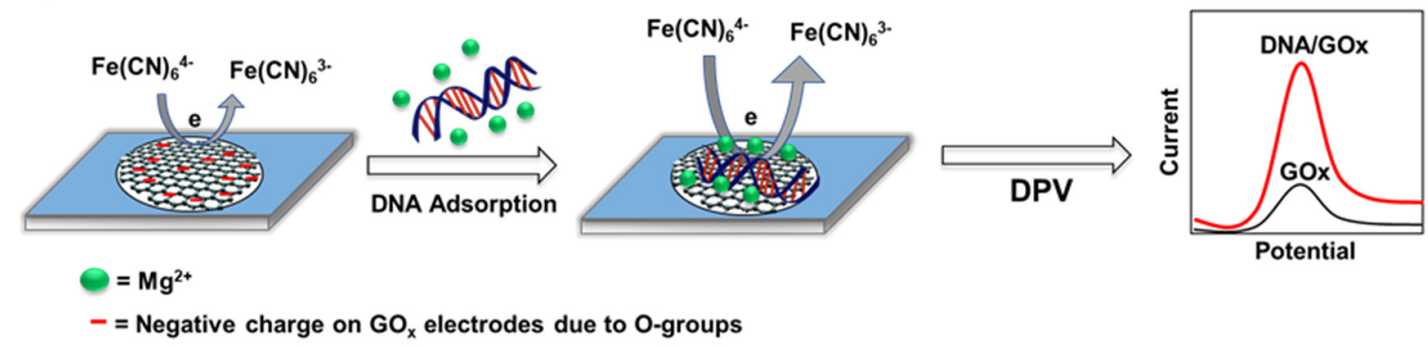

Scheme 1. (a) Illustrating fabrication of electrodes by inkjet printing of exfoliated few-layered oxygen functionalized graphene $\left(\mathrm{GO}_{\mathrm{x}}\right)$ on indium tin oxide substrate, followed by adhesion of a vinyl mask selectively exposing a $\mathrm{GO}_{\mathrm{x}}$ surface with $2 \mathrm{~mm}$ diameter. (b) Depiction of sensing mechanism: the lower current on the unmodified electrode is due to the repulsion between the negatively charged redox probe and the negative O-groups on the $\mathrm{GO}_{\mathrm{x}}$ surface. Adsorption of DNA sequence on a $\mathrm{GO}_{\mathrm{x}}$ surface in presence of $\mathrm{Mg}^{2+}$ ions reduces the electrostatic repulsion, which leads to higher diffusion of the redox probe producing higher electrochemical current measured by DPV. 


\section{Experimental}

\subsection{Materials}

For the sequence type, trinucleotide repeats sequences (TNRs) were used with CGG, CAG, and GAA repeats. All the synthetic TNR oligos were purchased from Integrated DNA Technologies (Coralville, IA, USA). The different sequences and lengths of the TNRs are shown in Table S1. Graphite flakes, $99 \%$ carbon basis ( -325 mesh particle size, $\geq 99 \%$ ), ethyl cellulose with viscosity $4 \mathrm{cP}(5 \%)$ in toluene/ethanol 80:20 (lit), and 48\% ethoxyl, $\alpha$-Terpineol $(90 \%)$, tris(hydroxymethyl)aminomethane $\left(\right.$ Tris- $\left.\mathrm{ClO}_{4}\right)$ were purchased from Sigma-Aldrich (St Louis, MO, USA). Ethanol (95\%); cyclohexanone, $\mathrm{K}_{4}\left[\mathrm{Fe}(\mathrm{CN})_{6}\right]$, $\mathrm{K}_{3}\left[\mathrm{Fe}(\mathrm{CN})_{6}\right](99+\%)$, and phosphate-buffered saline (PBS) pH $7.4(5 \times$ solution) were purchased from Fisher Scientific. Holey carbon-coated grids for electron microscopic studies were purchased from SPI Supplies (West Chester, PA, USA). Indium tin oxide coated substrate (ITO) with resistivity $4-8 \Omega$ /sq was obtained from Delta Technologies (Loveland, CO, USA). An Electrochemical Workstation CHI 660E from CHI Instruments (Austin, TX, USA) was used for electrochemical characterization of the interface. A Metrohm Autolab potentiostat was used for differential pulse voltammetry measurements. An Ag/ AgCl (with $\mathrm{KCl}$ solution) reference electrode and platinum wire auxiliary electrode was procured from Bioanalytical Systems Inc. (West Lafayette, IN, USA). Fujifilm Dimatix Materials Printer (DMP-2800) was used for printing on ITO substrate and purchased from Integrity Industrial Inkjet Integration (W. Lebanon, NH, USA). A NanoDrop One Spectrometer from Thermo Scientific was used for UV-Visible characterization of the few-layered graphene ink. A Graphtec Cutting Plotter (CE6000-40) was used to cut vinyl sheets to be used for covering the ITO substrates, while exposing a $2 \mathrm{~mm}$ diameter circle for studying the interface. Open-source software, Inkscape (Version 0.91), was used to design patterns for printing. A portable four-point probe test meter (HM21) from Jandel Engineering Limited (UK) was used for electrical characterization of the printed graphene ink. Raman characterization of graphene ink was performed using a Horiba iHR550 imaging spectrometer with nearinfrared (NIR) excitation light source at a wavelength of $\sim 785 \mathrm{~nm}$ (iBeam-Smalt-785-S-WS, TOPTICA Photonics). A Hitachi H-7650 transmission electron microscope operating at $60 \mathrm{kV}$ and a Quanta 450 FEG (FEI) at the SIU Imaging Center were used for electron microscopic characterization of graphene ink and fabricated devices. Dynamic Light Scattering (DLS) measurements were performed using a DynaPro NanoStar purchased from Wyatt Technology Corporation.

\subsection{Preparation of Ink}

First, graphene sheets were exfoliated by ultrasonic exfoliation of graphite flakes in ethyl cellulose/ethanol mixture using an ultrasonication method as reported earlier [25,26], which gives a solid product of graphene/ethyl cellulose (Gr/EC). To prepare the graphenebased ink for inkjet printing, the Gr/EC powder was dispersed in an 83:17 cyclohexanone/terpineol mixture, sonicated for $2.5 \mathrm{~h}[25,26]$, and stored at room temperature. For inkjet printing, 3.5\% ink concentration was prepared having $10 \mathrm{cP}$ viscosity, which is suitable for inkjet printing using Dimatix printer.

\subsection{Characterization of Ink}

For ink characterization, a UV-vis spectrum scan of the ink was obtained between $200-800 \mathrm{~nm}$ by dropping a $5 \mu \mathrm{L}$ aliquot of the ink on the NanoDrop Spectrometer. Transmission electron microscopic (TEM) images of the graphene nanosheets in the ink were obtained by dropping a small amount of the ink on a holey carbon coated grid followed by air drying before imaging. To measure the particle size of the ink, $200 \mu \mathrm{L}$ of the sample was diluted up to $50 \mathrm{~mL}$ using absolute ethanol as a solvent. The mixture was sonicated for one minute. The DLS analysis was performed using $300 \mu \mathrm{L}$ of the solution. This dilution factor allowed a mostly translucent solution to be analyzed. To confirm the type of graphene material, the ink was analyzed by Raman spectroscopy after annealing at $350{ }^{\circ} \mathrm{C}$. The ink was directly analyzed on glass slides (Eisco microscope slides) using a modular Ra- 
man microscope system. A grating of $600 \mathrm{~g} / \mathrm{mm}$ was used in the spectrometer, and a CCD camera on the Raman microscope was used to locate the ink deposition. After performing the characterization tools mentioned above, we identified our ink as few-layered oxygen functionalized graphene $\left(\mathrm{GO}_{\mathrm{x}}\right)$.

\subsection{Fabrication and Characterization of $\mathrm{GO}_{x}$ Electrodes}

The $\mathrm{GO}_{\mathrm{x}}$ ink was printed on ITO substrates using a Dimatix inkjet printer, employing parameters as previously reported [26]. For resistance measurements, line patterns were printed on ITO using printing cycles $(3,5$, and 7$)$ and sintered in a furnace for $30 \mathrm{~min}$ at $350{ }^{\circ} \mathrm{C}$. Later, thicknesses of the patterned lines from different cycles were measured by scanning electron microscopy (SEM) before and after sintering.

Circular graphene patterns $2 \mathrm{~mm}$ in diameter were printed on the clean and dry ITO substrates for DNA adsorption studies. Following printing, thermal annealing of the electrodes was performed at various temperatures $\left(250{ }^{\circ} \mathrm{C}\right.$ to $\left.350{ }^{\circ} \mathrm{C}\right)$ in air for $30 \mathrm{~min}$. The working electrode area was separated from the rest of the ITO surface by pasting a vinyl sheet on the surface with a $2 \mathrm{~mm}$-diameter hole to expose the inkjet-printed electrode while covering the rest of the electrically conducting area. The electrochemical impedance spectroscopy (EIS) was performed in the presence of $1 \mathrm{mM} \mathrm{K}_{4}\left[\mathrm{Fe}(\mathrm{CN})_{6}\right] / \mathrm{K}_{3}\left[\mathrm{Fe}(\mathrm{CN})_{6}\right]$ (1:1) prepared in PBS buffer ( $\mathrm{pH} 7.2)$ at $0.3 \mathrm{~V}$ against $\mathrm{Ag} / \mathrm{AgCl}$ reference $(3 \mathrm{M} \mathrm{KCl})$ using $5 \mathrm{mV}$ amplitude and $100 \mathrm{kHz}$ to $0.1 \mathrm{~Hz}$ frequency. Then, cyclic voltammetry with a potential window of $0-0.6 \mathrm{~V}$ was performed at the scan rates of $50-500 \mathrm{mV} / \mathrm{s}$ in $1 \mathrm{mM}$ $\mathrm{K}_{4}\left[\mathrm{Fe}(\mathrm{CN})_{6}\right] / \mathrm{K}_{3}\left[\mathrm{Fe}(\mathrm{CN})_{6}\right]$ (1:1) prepared in PBS buffer (pH 7.2). The electrochemical measurements were recorded against an $\mathrm{Ag} / \mathrm{AgCl}$ reference electrode and a platinum wire counter electrode.

\subsection{Electrochemical Study of DNA/GO $\mathrm{I}_{x}$ Interface}

Solution hybridized double-stranded DNA (dsDNA) were prepared in $100 \mu \mathrm{M}$ Tris buffer ( $\mathrm{pH} 8.5$ ) containing $200 \mathrm{mM} \mathrm{NaCl}$ and $20 \mathrm{mM} \mathrm{MgCl}_{2}$. The mixture was heated to the melting temperature for $30 \mathrm{~min}$ and annealed at room temperature for $1 \mathrm{~h}$. For electrochemical characterization of the DNA/GO interface, $5 \mu \mathrm{L}$ aliquots of DNA solution were dropped on the $\mathrm{GO}_{\mathrm{x}}$ electrode and incubated for $12-16 \mathrm{~h}$ at $4{ }^{\circ} \mathrm{C}$. For concentrationdependence study, a range from $1 \mathrm{aM}$ to $10 \mathrm{nM}$ was used to adsorb dsDNA (dsCGG-8, dsCAG-8, and dsGAA-8; see Table S1) on the $\mathrm{GO}_{x}$ surface. For the length-dependence study, 5, 8, and 10 repeat lengths of 1 aM dsCGG were adsorbed on the $\mathrm{GO}_{\mathrm{x}}$ surface. For surface hybridization detection, concentration of the physisorbed probe sequence (ssCGG-8) was first optimized, and later exposed to complementary GGC-8 target and noncomplementary sequences (NC-1 = TTC-8 and NC-2 = CAG-8) at 1 aM concentration. To confirm the ionic strength effect on the adsorption, EDTA was added to the DNA solution to chelate $\mathrm{Mg}^{2+}$ before the adsorption on the $\mathrm{GO}_{\mathrm{x}}$ surface. Following the adsorption of the sequences for various variables, differential pulse voltammetry was performed with a potential range of $0.1-0.5 \mathrm{~V}$ and an amplitude of $0.05 \mathrm{~V}$ in $1 \mathrm{mM} \mathrm{Fe}(\mathrm{CN})_{6}{ }^{3-/ 4-}$ prepared in PBS buffer ( $\mathrm{pH} 7.2$ ).

\section{Results and Discussion}

Figure 1a illustrates the graphene-based ink preparation in an environmentally benign solvent as reported previously [25-27], which was found stable even after 15 months of storage at room temperature. The graphene-based ink was characterized by TEM, as shown in Figure 1b, indicating that the process yielded few-layered graphene nanosheets. The UV-vis characterization shown in Figure 1c confirms the formation of graphene sheets with a strong absorption peak at $275 \mathrm{~nm}$ due to excitation of $\pi$-plasmon of graphitic structure, which corroborates the previous reports [28-30]. The bands shown in the Raman spectrum in Figure $1 \mathrm{~d}$ are similar to annealed exfoliated graphene comprising four bands, i.e., $\mathrm{G}$ band at $\sim 1590 \mathrm{~cm}^{-1}, 2 \mathrm{D}$ band at $\sim 2700 \mathrm{~cm}^{-1}$, and disorder-related $\mathrm{D}$ and $\mathrm{D}^{\prime}$ peaks at $\sim 1350$ and $\sim 1620 \mathrm{~cm}^{-1}$, respectively [27]. The sharpness of the D and $G$ bands are similar 
to the graphene-ethylene cellulose nanocomposite [27]. As previously indicated, a lower value of the $\mathrm{I}(\mathrm{D}) / \mathrm{I}(\mathrm{G})$ peak ratio suggests an increase in graphitization and lower defects, which can lead to better electrical conductivity [31]. Moreover, defects and oxidation might be introduced in the material during the sonication and annealing process, and may also arise from the smaller sizes of the sheets $[27,32]$. The $\mathrm{I}(\mathrm{D}) / \mathrm{I}(\mathrm{G})$ value for this ink is $\sim 0.58$, which indicates a moderate level of defects and oxidation during exfoliation and annealing [27], while the sharp peaks confirm the improved graphitization compared to typical graphene oxide (GO) material [33]. The composition of the ink was verified by EDS elemental analysis (Figure S1 in Supplementary Information) showing 56\% C-atoms and $34 \%$ O-atoms after sintering the surface yielding a $\mathrm{C} / \mathrm{O}$ ratio $=1.5$, which confirms the partial oxidation of the ink during the formulation and annealing process. Figure 1e shows the particle size distribution of $82 \%$ of the particles with a diameter in the range of 250 to $700 \mathrm{~nm}$, with an average diameter of $432 \mathrm{~nm}$. The extensive characterization presented here suggests the ink material as few-layered oxygen-functionalized graphene ink $\left(\mathrm{GO}_{\mathrm{x}}\right)$, where the presence of a moderate amount of oxygen functional groups on the surface may facilitate intermediate loadings and binding interactions for DNA [34].

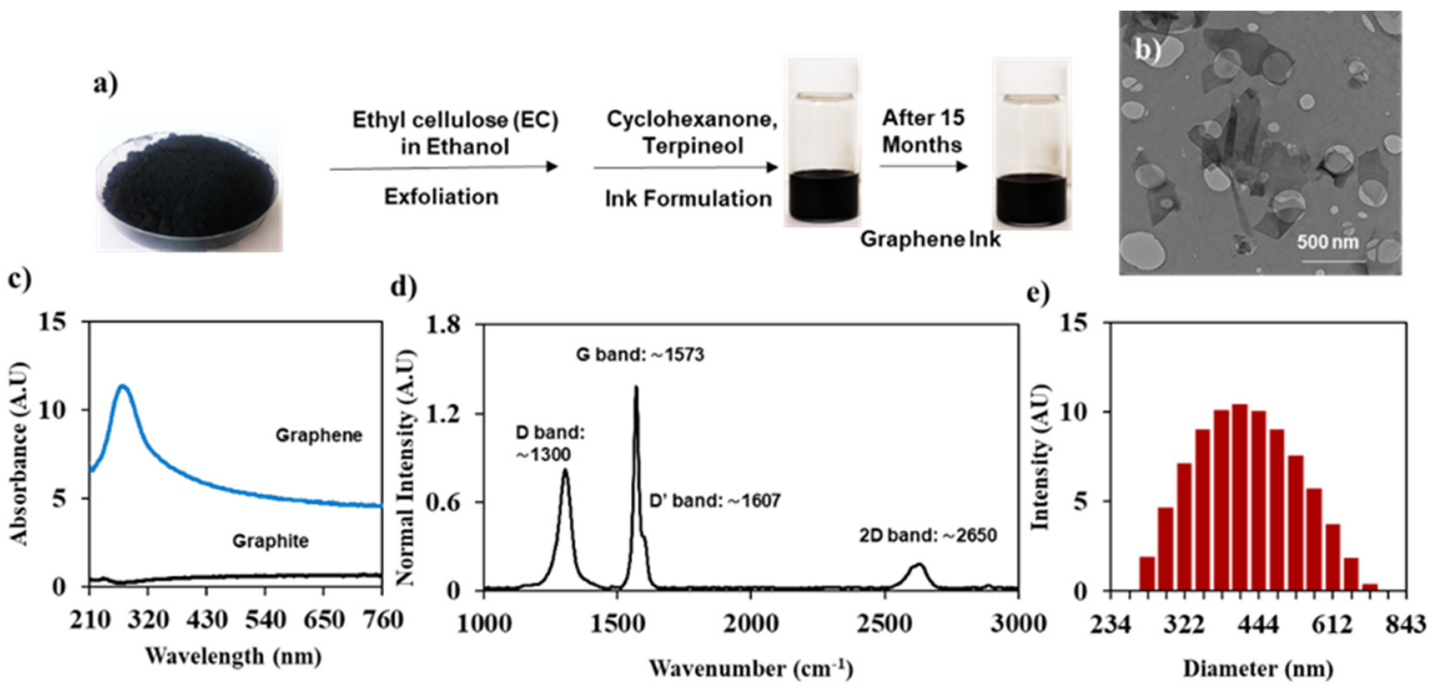

Figure 1. Synthesis and characterization of the few-layered graphene ink. (a) Exfoliation and formulation, (b) TEM image of exfoliated graphene sheets, (c) UV-vis spectrum of graphite and graphene ink, (d) Raman spectra of the ink, and (e) dynamic light scattering of the ink.

The $\mathrm{GO}_{\mathrm{x}}$ ink was printed and characterized by various methods. We investigated the relationship between the printing cycles and pattern thickness by SEM shown in Figure 2 . The cross-section images of 3,5, and 7 printing cycles of $\mathrm{GO}_{\mathrm{x}}$ patterns following sintering at $300{ }^{\circ} \mathrm{C}$ (Figure 2a) confirm the increase in thickness of the printed pattern with the number of printing cycles, i.e., 3 cycles $(0.75 \mu \mathrm{m}), 5$ cycles $(1.5 \mu \mathrm{m})$, and 7 cycles $(2.4 \mu \mathrm{m})$. The morphology of the $\mathrm{GO}_{\mathrm{x}}$ surface reveals a smooth surface before sintering, and the appearance of wrinkles after sintering. Such wrinkled roughness may endow a material with higher electrochemical current due to an increase in the surface area, as previously reported $[35,36]$. Then, we investigated the electrical and electrochemical behavior of the $\mathrm{GO}_{x}$ electrode. Figure 3 a shows that the resistivity significantly decreased with high precision when the sintering temperature reached at $350{ }^{\circ} \mathrm{C}$. Figure $3 \mathrm{~b}$ indicates that the trend decreases with the printing cycles, where five cycles have significantly higher precision. Figure $3 c$ shows the Nyquist form of electrochemical impedance spectroscopy (EIS) plots for the bare ITO substrate (see inset), $\mathrm{GO}_{\mathrm{x}}$ ink before sintering, and $\mathrm{GO}_{\mathrm{x}}$ ink after sintering (see inset). The charge transfer resistance of the $\mathrm{GO}_{\mathrm{x}}$ ink before sintering $\left(\mathrm{R}_{\mathrm{ct}}=246 \mathrm{k} \Omega\right)$ is almost two orders of magnitude higher than that of bare ITO $\left(R_{c t}=9.5 \mathrm{k} \Omega\right)$. While the charge transfer resistance of the $\mathrm{GO}_{\mathrm{x}}$ ink following sintering decreased $\left(\mathrm{R}_{\mathrm{ct}}=4.2 \mathrm{k} \Omega\right)$, 
which is less than $50 \%$ of the bare ITO resistance. This is an indication of substantially improved electrochemical property of the $\mathrm{GO}_{\mathrm{x}} / \mathrm{ITO}$ electrode after sintering. The modified Randle's equivalent circuit model used for fitting the Nyquist plot and the fitting values are shown in Figure S2 and Table S2, respectively. Following this characterization, we used the conditions of five printing cycles and sintering at $350{ }^{\circ} \mathrm{C}$ for $30 \mathrm{~min}$ to study the $\mathrm{DNA} / \mathrm{GO}_{\mathrm{x}}$ interface.

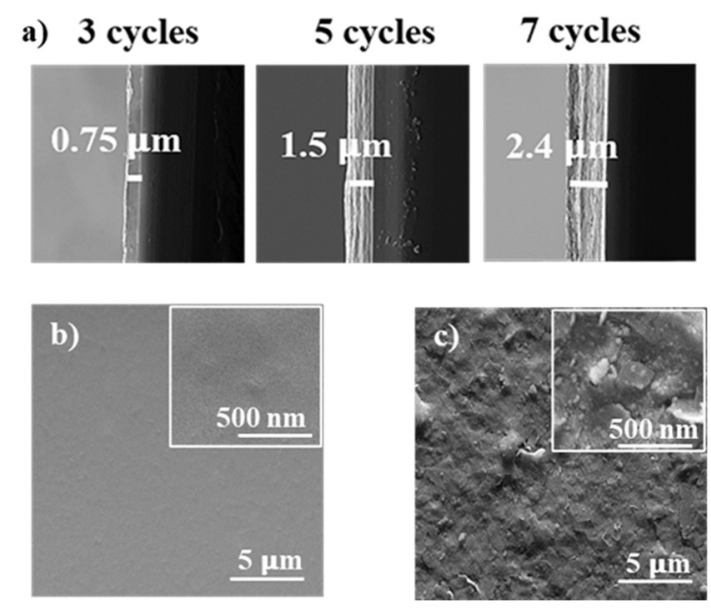

Figure 2. (a) SEM images of 3, 5, and 7 printed cycles of $\mathrm{GO}_{x}$ ink after sintering at $300{ }^{\circ} \mathrm{C}$. (b) SEM images of top surface of the printed $\mathrm{GO}_{\mathrm{x}}$ electrode before sintering and (c) after sintering.
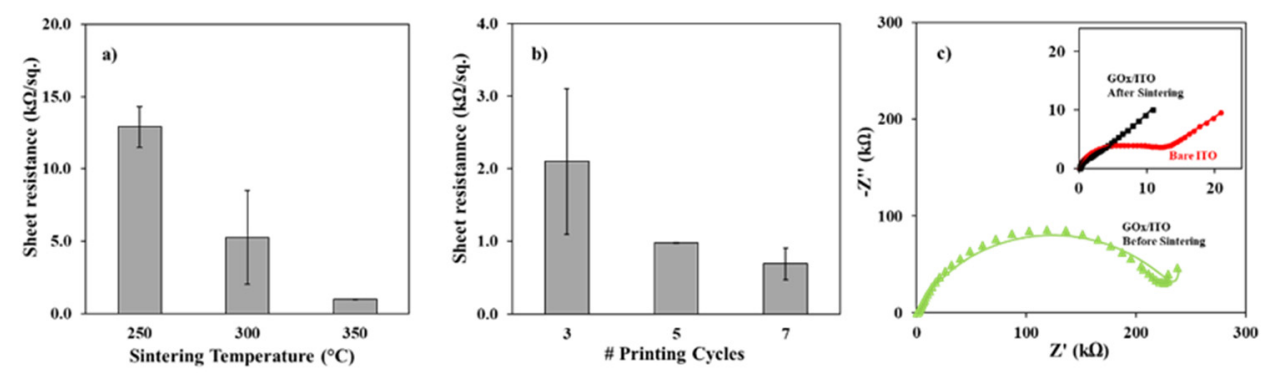

Figure 3. (a) Resistivity versus sintering temperature for $30 \mathrm{~min}$ following five printing cycles. (b) Resistivity versus number of printing cycles following sintering under fixed conditions $\left(350{ }^{\circ} \mathrm{C}\right.$ for $30 \mathrm{~min}$ ). (c) Nyquist form of the EIS plot for bare ITO and $\mathrm{GO}_{\mathrm{x}} / \mathrm{ITO}$ (before and after sintering).

The electrochemical current of the surface-adsorbed dsCGG-8 (10 nM) was investigated on the $\mathrm{GO}_{\mathrm{x}}$ electrode by voltametric techniques. Figure 4a shows cyclic voltametric curves before and after DNA modification of the $\mathrm{GO}_{\mathrm{x}}$ electrode. The integrated peak current of the dsCGG-8/GO $(12.5 \mu \mathrm{A})$ is almost twice the $\mathrm{GO}_{\mathrm{x}}$ current $(6.5 \mu \mathrm{A})$. The enhanced charge transport behavior of the DNA modified $\mathrm{GO}_{\mathrm{x}}$ electrode was monitored over a range of $50-500 \mathrm{mV} / \mathrm{s}$ scan rates (Figure $4 \mathrm{~b}$ ), which follows the Randles-Sevcik equation model wherein peak current is proportional to square root of the scan rate [37]. However, Figure $4 \mathrm{c}$ shows that cathodic-anodic peaks separation $\left(\Delta \mathrm{E}_{\mathrm{p}}\right)$ increases with the scan rate (see cyclic voltamogram in Figure S3), which is an indicative of a quasi-reversible electron kinetics at the electrode surface and is typical to the DNA modified electrodes [38]. Figure $4 \mathrm{~d}$ shows the cyclic voltammetry performed up to 50 scans for the DNA modified $\mathrm{GO}_{\mathrm{x}}$ electrode, which presents no substantial change in the peak current and overpotential with the number of scans, thus it suggests a stable DNA/GO interface. We attribute this strong adsorption affinity to mild oxidation of the graphene sheets in the $\mathrm{GO}_{\mathrm{x}}$ ink $(\mathrm{C} / \mathrm{O}=1.5)$, similar to recently reported strong adsorption of ssDNA and dsDNA on graphdiyne surface with a low oxidation degree [39]. Moreover, high cationic strength screens negative charge between the two materials and facilitates the adsorption. There is an intriguing question of whether this current enhancement is due to the DNA mediated 
electron transport or enhanced diffusion of the redox probe owing to high cationic strength environment. To test the effect, we added EDTA in the DNA solutions to chelate the $\mathrm{Mg}^{2+}$, followed by incubation of the mixture with the $\mathrm{GO}_{x}$ electrode. Figure 5 shows the DPV current of ssCGG- 8 and dsCGG- 8 in the presence and absence of $\mathrm{Mg}^{2+}$ and compared with the unmodified $\mathrm{GO}_{\mathrm{x}}$ electrode current. Evidently, the current in the absence of $\mathrm{Mg}^{2+}$ is very similar to background current or unmodified $\mathrm{GO}_{x}$ current $(\sim 22 \mu \mathrm{A})$. This result confirms the dual role of $\mathrm{Mg}^{2+}$, i.e., promoting the DNA adsorption as suggested previously [15], and reducing the electrostatic repulsion between the redox probe and the electrode surface. It is important to note that DNA modified electrodes have shown higher resistance to charge transfer than that of unmodified electrode in low cationic strength due to lack of diffusion of the redox probe [40], which was improved after the addition of divalent cations [41-43]. Based on these results, we conclude that the high concentration of divalent cations in the environment screen the negative charge on both materials, which ultimately increases the diffusion of the redox probe, $\mathrm{Fe}(\mathrm{CN})_{6}{ }^{3-/ 4-}$, to the electrode surface leading to higher current response.
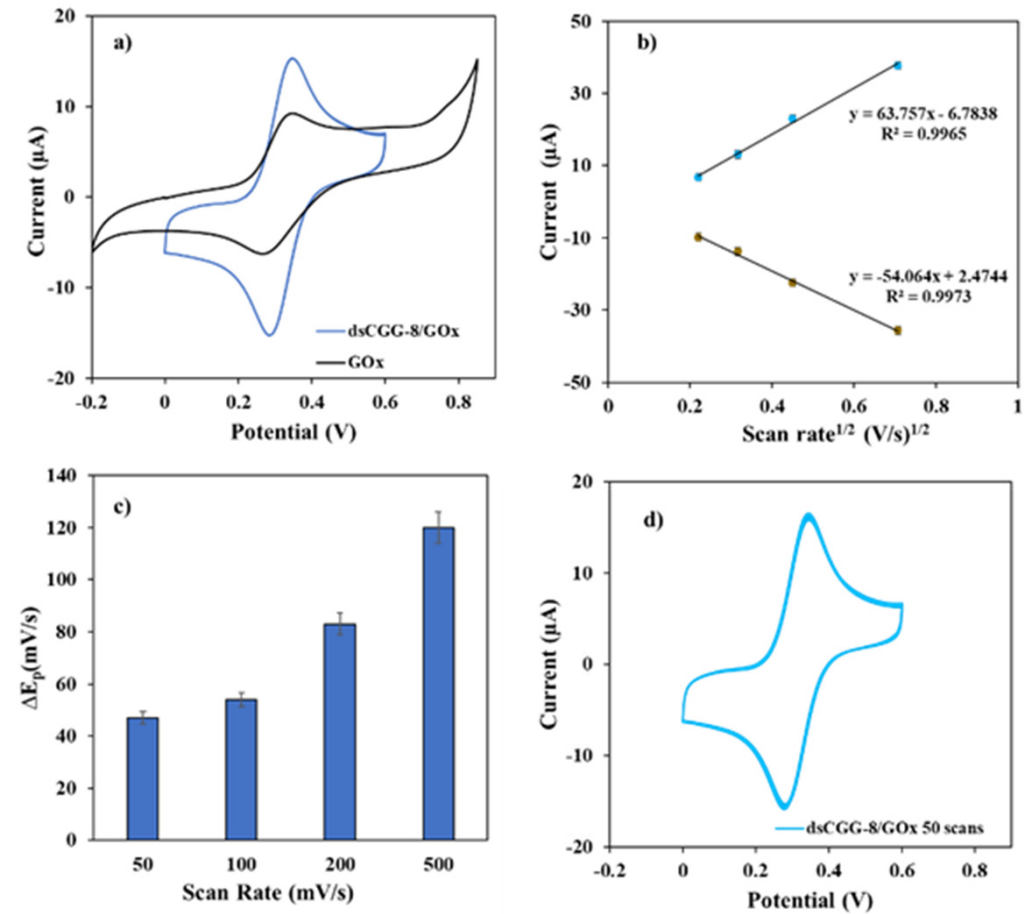

Figure 4. (a) Cyclic voltametric curves before and after adsorption of dsCGG-8 on $\mathrm{GO}_{\mathrm{x}}$. (b) Plot of cathodic and anodic voltametric current of dsCGG-8 as a function of square root of scan rate. (c) Cathodic-Anodic peaks separation $\left(\Delta \mathrm{E}_{\mathrm{p}}\right)$ versus scan rate for the dsCGG-8 modified electrodes. (d) 50 scans of $\mathrm{CV}$ curves of dsCGG-8 on $\mathrm{GO}_{\mathrm{x}}$ electrode. The electrochemical measurements were performed in presence of $1 \mathrm{mM} \mathrm{Fe}(\mathrm{CN})_{6}{ }^{3-/ 4-}$ using Pt wire counter electrode and $\mathrm{Ag} / \mathrm{AgCl}$ $(3 \mathrm{M} \mathrm{KCl})$ reference electrode. Scan rate for $\mathrm{CV}$ measurement is $100 \mathrm{mV} / \mathrm{s}$. Concentration of dsCGG-8 was $10 \mathrm{nM}$.

Next, we tested the current responses of conformation, concentration, length, and sequence types of DNA using DPV. Figure 6a shows the DPV curves of $\mathrm{GO}_{\mathrm{x}}$, ssCGG-8, dsCGG-8, and a noncomplementary mixture of CGG-8/CAG-8 at $10 \mathrm{nM}$ concentration. The current response of the double-stranded conformation (dsCGG-8) was higher than the single-stranded conformation (ssCGG-8), while the current response of the noncomplementary mixture showed similar current response as the single-stranded conformation, which corroborates the fact that noncomplementary strands remained unhybridized and in single-stranded conformation. Figure $6 \mathrm{~b}$ shows the current response of dsCGG-8 over a range of $1 \mathrm{aM}$ to $10 \mathrm{nM}$. The least-squares regression for dsCGG-8 formed a linear curve fit 
with a correlation coefficient $\mathrm{R}^{2}=0.9785$ (Figure $6 \mathrm{~b}$ ). The detection limit signal, $\mathrm{LOD}_{y}$, was obtained using $\mathrm{LOD}_{y}=\left(\right.$ blank signal $\left.+3^{*} \mathrm{SD}_{\text {blank }}\right)-$ intercept; where blank signal $=22 \mu \mathrm{A}$, $3^{*} \mathrm{SD}_{\text {blank }}=3^{*} 2.5 \mu \mathrm{A}$, and intercept $=46.566 \mu \mathrm{A}$. Then, the 'theoretical' limit of detection concentration, $\mathrm{LOD}_{x}$, was determined as $0.8 \mathrm{aM}$ by calculating antilog ( $\mathrm{LOD}_{y} \div$ sensitivity), where sensitivity or the slope of the curve ' $\mathrm{m}$ ' is 0.9338 . Figure $6 \mathrm{c}$ shows the current responses of dsCGG comprising 5, 8, and 10 dsCGG repeat units (i.e., 15, 24, and 30 nucleotide lengths respectively) at $1 \mathrm{aM}$ concentration regime. The upward trend of the current response with respect to length indicates that the increase in DNA adsorption aided by $\mathrm{Mg}^{2+} \mathrm{fa}-$ cilitates the charge transport at the interface. This length-dependent current response may lead to sensitive and label-free discrimination of normal and abnormal lengths of DNA repeat sequences associated with neurodegenerative diseases, as reported recently on $\mathrm{MoS}_{2}$ nanosheets surfaces [44]. Then, we tested the adsorption of various single-stranded, double-stranded, and noncomplementary sequences of same length (i.e., 8 trinucleotide repeats or 24 nucleotides) at $10 \mathrm{nM}$ concentration. Figure $6 \mathrm{~d}$ shows the current responses of trinucleotide repeat types CGG, CAG, and GAA (single-, double-, and noncomplementary) revealing the following trends. First, the current responses of double-stranded conformations, in all cases, are higher than their single strands. Second, the noncomplementary responses are similar to single-stranded conformation. Third, the current responses for all sequences are similar with respect to their conformation. Overall, we learn that the increase in DNA interaction with the surface in the high cationic environment increases the current response, which can be indicative of its conformation, concentration, and length. Despite the differential adsorption affinity of graphene-based materials for different nucleotide types, the DNA adsorption was sequence-independent. This result can be rationalized as the effect of high concentration of $\mathrm{Mg}^{2+}$ perhaps masks the sequence-dependent affinity between DNA and $\mathrm{GO}_{\mathrm{x}}$.

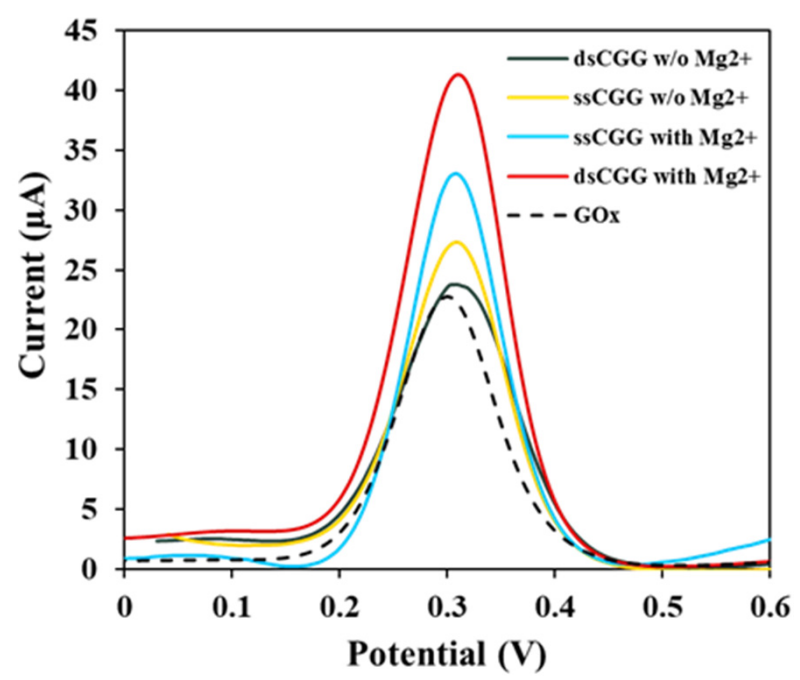

Figure 5. DPV curves of unmodified $\mathrm{GO}_{\mathrm{x}}$ and after exposure to $10 \mathrm{nM}$ ssCGG-8 and dsCGG-8 in presence (with) and absence (w/o) of $\mathrm{Mg}^{2+}$.

Finally, we tested the performance of the interface for biosensing application. We optimized the adsorption of the probe sequence, ssCGG-8, which was later exposed to a complementary target and two different noncomplementary sequences. Figure 7a shows the response of ssCGG-8 probe sequence between $0.1 \mathrm{pM}-10 \mu \mathrm{M}$ concentrations. The maximum current of $32.3 \pm 1.2 \mu \mathrm{A}$ was observed at $1 \mathrm{nM}$ concentration, which was assumed to be saturation of the surface with the probe strands. The current responses in Figure $7 \mathrm{~b}$ show significant enhancement in the current following the surface hybridization reaction with the complementary target (CCG-8) at $1 \mathrm{aM}$ concentration. The change in current $\Delta \mathrm{I}$, which is (target current-probe current), shown in Figure 7c, evidently distinguishes between the complementary target and the noncomplementary sequences (NC- $1=$ TTC- 8 
and NC-2 = CAG-8). One may notice that the current enhancement of surface hybridized complex is much higher than the solution hybridized complex at this concentration regime, which intrigued us to study the effect of target concentration, as shown in Figure 7d. Although current was enhanced following hybridization over a wide concentration range of the target, $\Delta \mathrm{I}$ shows a downward trend with the target concentration. As mentioned above, competitive binding between nucleobases and graphene oxide (GO) exist, leading to partial denaturation of double-stranded DNA [24]. Based on this knowledge, we rationalize that not all target strands will hybridize on the surface, and unhybridized target strands may adsorb non-specifically on the pre-saturated interface, leading to a decrease in current by impeding diffusion of the redox probe. Nevertheless, further investigation is necessary to rationalize the high sensitivity at very low target concentration and the downward concentration trend. We propose that, in future applications, the strong adsorption of the probe in the presence of $\mathrm{Mg}^{2+}$ and intense surface hybridization signal would eliminate the steps involved in covalent immobilization of a probe (chemisorption) [14] or expensive modification of the probe with 1-pyrenebutanoic acid succinimidyl ester (PASE) linker for stronger $\pi-\pi$ interactions with graphene surface [45]. In contrast to other electrochemical detection of TNRs [46,47], this label-free $\mathrm{GO}_{\mathrm{x}}$ platform does not rely on guanine oxidation for sensing - therefore, a noninvasive method-and shows higher sensitivity down to the attomolar level compared to a recently reported solution-gated graphene transistor having detection limit only up to femtomolar range.
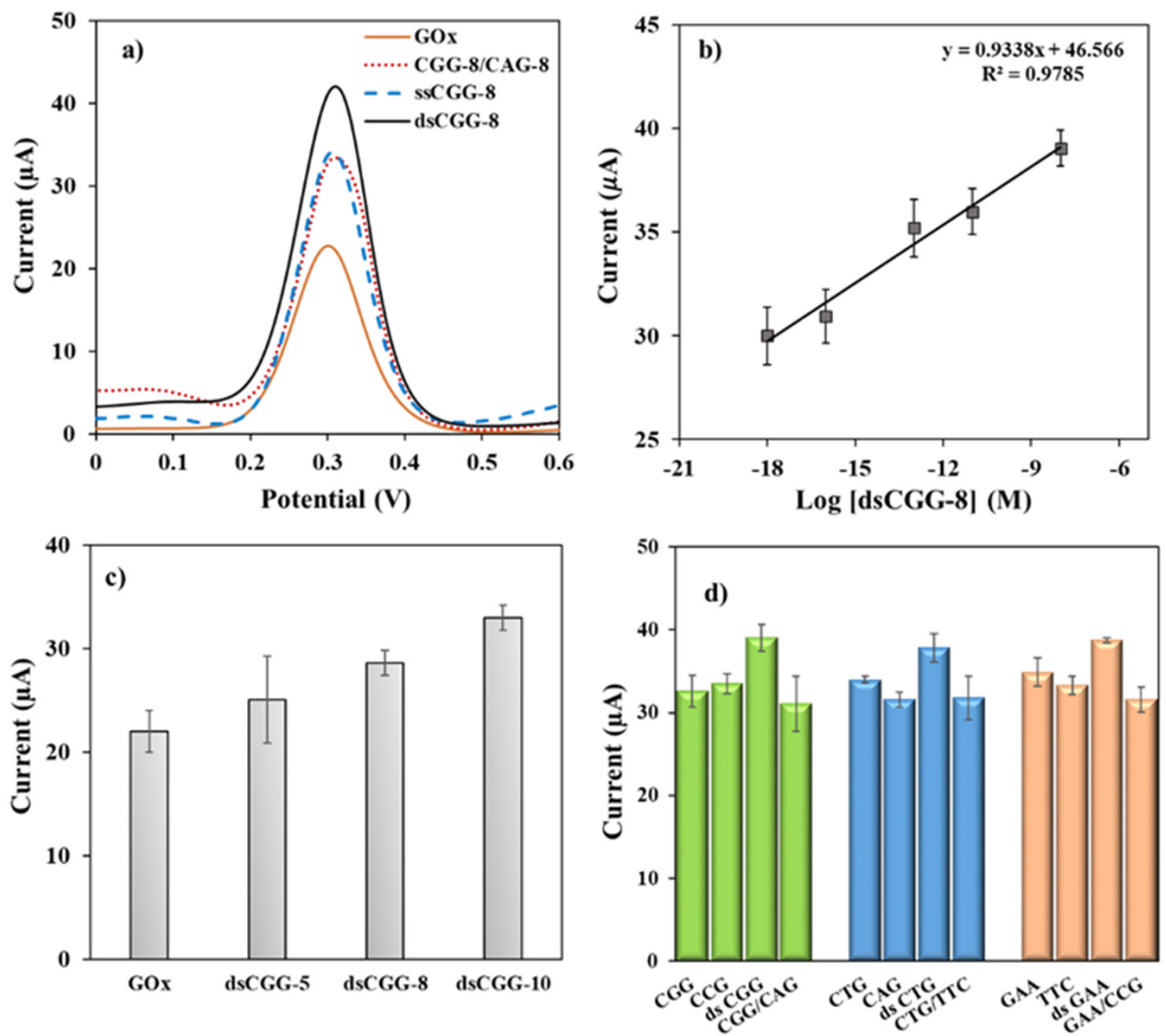

Figure 6. (a) Differential pulse voltamogram of $10 \mathrm{nM}$ ssCGG-8, dsCGG-8, and noncomplementary mixture CGG-8/CAG-8. (b) Calibration curve dsCGG-8. (c) DPV current response of various lengths of dsCGG at 1 aM concentration. (d) DPV current response of various single-stranded, doublestranded, and noncomplementary sequences at $10 \mathrm{nM}$ concentration. Error bars represent standard deviation for $\mathrm{N} \geq 3$. 

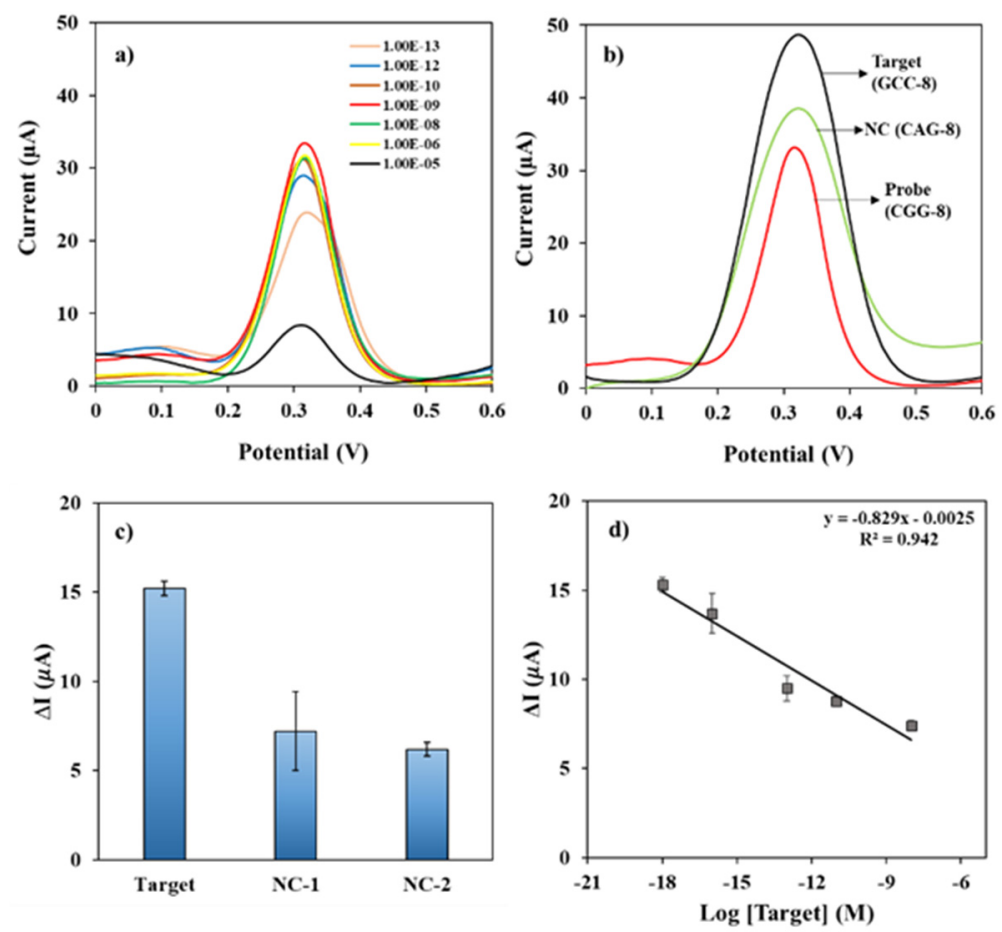

Figure 7. DPV current of (a) different concentration of probe sequence (ssCGG-8), (b) 1 nM probe, surface hybridized target (GGC-8) and noncomplementary (CAG-8) at 1 aM concentration. (c) Difference in current $\Delta \mathrm{I}$ (target current - probe current) for complementary (CCG-8) and noncomplementary targets (NC-1 = TTC-8 and NC-2 = CAG- 8 ), and (d) $\Delta$ I versus concentration of the surface hybridized CCG-8 [Target]. Hybridization time $1 \mathrm{~h}$.

\section{Conclusions}

To best of our knowledge, this is the first comprehensive study on the electrochemical behavior of the DNA adsorbed, oxidized graphene electrodes $\left(\mathrm{GO}_{\mathrm{x}}\right)$. The $\mathrm{GO}_{\mathrm{x}}$ was synthesized and thoroughly characterized followed by fabrication of the $\mathrm{GO}_{\mathrm{x}}$ electrodes on ITO surfaces. The DNA adsorption on the $\mathrm{GO}_{\mathrm{x}}$ electrodes was performed in the high ionic strength $\left(20 \mathrm{mM} \mathrm{Mg}^{2+}+200 \mathrm{mM} \mathrm{Na}^{+}\right)$. The DNA-adsorbed $\mathrm{GO}_{\mathrm{x}}$ surfaces produced significantly higher current due to enhanced diffusion of the soluble redox probe, which was rationalized as the effect of high concentration of divalent cation $\left(\mathrm{Mg}^{2+}\right)$ in the environment. The study reveals that increase in DNA interaction with the surface increase the current response which can be indicative of its conformation, concentration, and length. The detection limit of the dsCGG adsorption on the $\mathrm{GO}_{\mathrm{x}}$ was $0.8 \mathrm{aM}$. The sequence-independent behavior was reasoned as the effect of high concentration of $\mathrm{Mg}^{2+}$ that neutralizes the negative charges on both materials and facilitates the adsorption of different types of sequences. Surface hybridization between the complementary sequences was distinguishable from the noncomplementary sequence, even at $1 \mathrm{aM}$ concentration regime. Nevertheless, further study is suggested to investigate the difference in concentration trends of solution versus surface hybridization. We propose that the strong DNA adsorption in presence of $\mathrm{Mg}^{2+}$ and intense surface hybridization signal can develop into simple and label-free DNA biosensors on inkjet-printed $\mathrm{GO}_{\mathrm{x}}$ devices.

Supplementary Materials: The following are available online at https:/ /www.mdpi.com/article/10 $.3390 /$ bios11080273/s1.

Author Contributions: Conceptualization: M.H.S.; Experimentation: N.A., T.E.H., I.M.S.; Formal analysis: N.A.; Supervision and Funding acquisition: M.H.S.; Resources (Raman and DLS): P.S. and B.M.G.; Writing and editing: S.T., B.M.G. and M.H.S. All authors have read and agreed to the published version of the manuscript. 
Funding: This research was funded by NSF (CBET-1940716 and CHE-1905341) and NIH support (5R21CA220137). The APC charges were supported by NSF (CBET-1940716).

Institutional Review Board Statement: Not applicable.

Informed Consent Statement: Not applicable.

Data Availability Statement: Not applicable.

Acknowledgments: M.H.S. acknowledges N.S.F. (CBET-1940716) to support this research. B.M.G. acknowledges N.S.F. and N.I.H. support (CHE-1905341 and 5R21CA220137) to support Ishani M. Senanayake.

Conflicts of Interest: Authors do not have any financial/commercial conflict of interest related to this manuscript.

\section{References}

1. Wei, Z.; Barlow, D.E.; Sheehan, P.E. The Assembly of Single-Layer Graphene Oxide and Graphene Using Molecular Templates. Nano Lett. 2008, 8, 3141-3145. [CrossRef]

2. Katsnelson, M.I. Graphene: Carbon in two dimensions. Mater. Today 2007, 10, 20-27. [CrossRef]

3. Shan, C.; Yang, H.; Song, J.; Han, D.; Ivaska, A.; Niu, L. Direct Electrochemistry of Glucose Oxidase and Biosensing for Glucose Based on Graphene. Anal. Chem. 2009, 81, 2378-2382. [CrossRef]

4. Bo, Y.; Yang, H.; Hu, Y.; Yao, T.; Huang, S. A novel electrochemical DNA biosensor based on graphene and polyaniline nanowires. Electrochim. Acta 2011, 56, 2676-2681. [CrossRef]

5. Li, D.; Zhang, W.; Yu, X.; Wang, Z.; Su, Z.; Wei, G. When biomolecules meet graphene: From molecular level interactions to material design and applications. Nanoscale 2016, 8, 19491-19509. [CrossRef] [PubMed]

6. Lu, C.H.; Yang, H.H.; Zhu, C.L.; Chen, X.; Chen, G.N. A graphene platform for sensing biomolecules. Angew. Chem. Int. Ed. Engl. 2009, 48, 4785-4787. [CrossRef] [PubMed]

7. Dong, X.; Shi, Y.; Huang, W.; Chen, P.; Li, L.-J. Electrical Detection of DNA Hybridization with Single-Base Specificity Using Transistors Based on CVD-Grown Graphene Sheets. Adv. Mater. 2010, 22, 1649-1653. [CrossRef]

8. Lin, C.-T.; Loan, P.T.K.; Chen, T.-Y.; Liu, K.-K.; Chen, C.-H.; Wei, K.-H.; Li, L.-J. Label-Free Electrical Detection of DNA Hybridization on Graphene using Hall Effect Measurements: Revisiting the Sensing Mechanism. Adv. Funct. Mater. 2013, 23, 2301-2307. [CrossRef]

9. Xu, H.; Dai, H.; Chen, G. Direct electrochemistry and electrocatalysis of hemoglobin protein entrapped in graphene and chitosan composite film. Talanta 2010, 81, 334-338. [CrossRef] [PubMed]

10. Han, Y.; Li, H.; Jafri, S.H.M.; Ossipov, D.; Hilborn, J.; Leifer, K. Optimization and analysis of pyrene-maltose functionalized graphene surfaces for Con A detection. Appl. Surf. Sci. 2020, 510, 145409. [CrossRef]

11. Jampasa, S.; Siangproh, W.; Laocharoensuk, R.; Vilaivan, T.; Chailapakul, O. Electrochemical detection of c-reactive protein based on anthraquinone-labeled antibody using a screen-printed graphene electrode. Talanta 2018, 183, 311-319. [CrossRef] [PubMed]

12. Zhao, J.; Lv, Y.; Kang, M.; Wang, K.; Xiang, Y. Electrochemical detection of protein by using magnetic graphene-based target enrichment and copper nanoparticles-assisted signal amplification. Analyst 2015, 140, 7818-7822. [CrossRef] [PubMed]

13. Zhang, H.; Li, Y.; Su, X. A small-molecule-linked DNA-graphene oxide-based fluorescence-sensing system for detection of biotin. Anal. Biochem. 2013, 442, 172-177. [CrossRef] [PubMed]

14. Lopez, A.; Liu, J. Covalent and Noncovalent Functionalization of Graphene Oxide with DNA for Smart Sensing. Adv. Intell. Syst. 2020, 2, 2000123. [CrossRef]

15. Wu, M.; Kempaiah, R.; Huang, P.-J.J.; Maheshwari, V.; Liu, J. Adsorption and Desorption of DNA on Graphene Oxide Studied by Fluorescently Labeled Oligonucleotides. Langmuir 2011, 27, 2731-2738. [CrossRef]

16. Tikum, A.F.; Ko, J.W.; Kim, S.; Kim, J. Reduced Graphene Oxide-Oligonucleotide Interfaces: Understanding Based on Electrochemical Oxidation of Guanines. ACS Omega 2018, 3, 15464-15470. [CrossRef]

17. Huang, P.-J.J.; Liu, J. Molecular Beacon Lighting up on Graphene Oxide. Anal. Chem. 2012, 84, 4192-4198. [CrossRef]

18. Antony, J.; Grimme, S. Structures and interaction energies of stacked graphene-nucleobase complexes. Phys. Chem. Chem. Phys. 2008, 10, 2722-2729. [CrossRef]

19. Zeng, S.; Chen, L.; Wang, Y.; Chen, J. Exploration on the mechanism of DNA adsorption on graphene and graphene oxide via molecular simulations. J. Phys. D Appl. Phys. 2015, 48, 275402. [CrossRef]

20. Zhao, X. Self-Assembly of DNA Segments on Graphene and Carbon Nanotube Arrays in Aqueous Solution: A Molecular Simulation Study. J. Phys. Chem. C 2011, 115, 6181-6189. [CrossRef]

21. Vovusha, H.; Sanyal, B. Adsorption of nucleobases on 2D transition-metal dichalcogenides and graphene sheet: A first principles density functional theory study. RSC Adv. 2015, 5, 67427-67434. [CrossRef]

22. Varghese, N.; Mogera, U.; Govindaraj, A.; Das, A.; Maiti, P.K.; Sood, A.K.; Rao, C.N.R. Binding of DNA Nucleobases and Nucleosides with Graphene. ChemPhysChem 2009, 10, 206-210. [CrossRef] [PubMed]

23. Ortmann, F.; Schmidt, W.G.; Bechstedt, F. Attracted by Long-Range Electron Correlation: Adenine on Graphite. Phys. Rev. Lett. 2005, 95, 186101. [CrossRef] [PubMed] 
24. Manohar, S.; Mantz, A.R.; Bancroft, K.E.; Hui, C.-Y.; Jagota, A.; Vezenov, D.V. Peeling Single-Stranded DNA from Graphite Surface to Determine Oligonucleotide Binding Energy by Force Spectroscopy. Nano Lett. 2008, 8, 4365-4372. [CrossRef] [PubMed]

25. Secor, E.B.; Prabhumirashi, P.L.; Puntambekar, K.; Geier, M.L.; Hersam, M.C. Inkjet Printing of High Conductivity, Flexible Graphene Patterns. J. Phys. Chem. Lett. 2013, 4, 1347-1351. [CrossRef] [PubMed]

26. Seo, J.-W.T.; Zhu, J.; Sangwan, V.K.; Secor, E.B.; Wallace, S.G.; Hersam, M.C. Fully Inkjet-Printed, Mechanically Flexible MoS2 Nanosheet Photodetectors. ACS Appl. Mater. Interfaces 2019, 11, 5675-5681. [CrossRef] [PubMed]

27. Liang, Y.T.; Hersam, M.C. Highly Concentrated Graphene Solutions via Polymer Enhanced Solvent Exfoliation and Iterative Solvent Exchange. J. Am. Chem. Soc. 2010, 132, 17661-17663. [CrossRef]

28. Wang, S.; Wang, C.; Ji, X. Towards understanding the salt-intercalation exfoliation of graphite into graphene. RSC Adv. 2017, 7, 52252-52260. [CrossRef]

29. Ji, Z.; Wu, J.; Shen, X.; Zhou, H.; Xi, H. Preparation and characterization of graphene/NiO nanocomposites. J. Mater. Sci. 2011, 46, 1190-1195. [CrossRef]

30. Bindumadhavan, K.; Srivastava, S.; Srivastava, I. Green Synthesis of Graphene. J. Nanosci. Nanotechnol. 2013, 13, 4320-4324.

31. Genc, R.; Alas, M.O.; Harputlu, E.; Repp, S.; Kremer, N.; Castellano, M.; Colak, S.G.; Ocakoglu, K.; Erdem, E. High-Capacitance Hybrid Supercapacitor Based on Multi-Colored Fluorescent Carbon-Dots. Sci. Rep. 2017, 7, 11222. [CrossRef] [PubMed]

32. Gao, W.; Alemany, L.B.; Ci, L.; Ajayan, P.M. New insights into the structure and reduction of graphite oxide. Nat. Chem. 2009, 1, 403-408. [CrossRef]

33. Jung, I.; Dikin, D.A.; Piner, R.D.; Ruoff, R.S. Tunable Electrical Conductivity of Individual Graphene Oxide Sheets Reduced at "Low" Temperatures. Nano Lett. 2008, 8, 4283-4287. [CrossRef] [PubMed]

34. Hong, B.J.; An, Z.; Compton, O.C.; Nguyen, S.T. Tunable Biomolecular Interaction and Fluorescence Quenching Ability of Graphene Oxide: Application to “Turn-on" DNA Sensing in Biological Media. Small 2012, 8, 2469-2476. [CrossRef] [PubMed]

35. Tite, T.; Chiticaru, E.A.; Burns, J.S.; Ioniţă, M. Impact of nano-morphology, lattice defects and conductivity on the performance of graphene based electrochemical biosensors. J. Nanobiotechnology 2019, 17, 101. [CrossRef] [PubMed]

36. Hwang, M.T.; Heiranian, M.; Kim, Y.; You, S.; Leem, J.; Taqieddin, A.; Faramarzi, V.; Jing, Y.; Park, I.; van der Zande, A.M.; et al. Ultrasensitive detection of nucleic acids using deformed graphene channel field effect biosensors. Nat. Commun. 2020, 11, 1543. [CrossRef]

37. Bard, A.J.; Faulkner, L.R. Electrochemical Methods: Fundamentals and Applications; Wiley: New York, NY, USA, 1980.

38. Li, C.-Z.; Long, Y.-T.; Kraatz, H.-B.; Lee, J.S. Electrochemical Investigations of M-DNA Self-Assembled Monolayers on Gold Electrodes. J. Phys. Chem. B 2003, 107, 2291-2296. [CrossRef]

39. Xiao, J.; Liu, Z.; Li, C.; Wang, J.; Huang, H.; Yi, Q.; Deng, K.; Li, X. Tunable graphdiyne for DNA surface adsorption: Affinities, displacement, and applications for fluorescence sensing. Anal. Bioanal. Chem. 2021, 413, 3847-3859. [CrossRef] [PubMed]

40. Asefifeyzabadi, N.; Taki, M.; Funneman, M.; Song, T.; Shamsi, M.H. Unique Sequence-Dependent Properties of Trinucleotide Repeat Monolayers: Electrochemical, Electrical, and Topographic Characterization. J. Mater. Chem. B 2020, 8, 5225-5233. [CrossRef]

41. Alam, M.N.; Shamsi, M.H.; Kraatz, H.-B. Scanning positional variations in single-nucleotide polymorphism of DNA: An electrochemical study. Analyst 2012, 137, 4220-4225. [CrossRef] [PubMed]

42. Shamsi, M.H.; Kraatz, H.-B. Probing nucleobase mismatch variations by electrochemical techniques: Exploring the effects of position and nature of the single-nucleotide mismatch. Analyst 2010, 135, 2280-2285. [CrossRef] [PubMed]

43. Taki, M.; Rohilla, K.J.; Barton, M.; Funneman, M.; Benzabeh, N.; Naphade, S.; Ellerby, L.M.; Gagnon, K.T.; Shamsi, M.H. Novel probes for label-free detection of neurodegenerative GGGGCC repeats associated with amyotrophic lateral sclerosis. Anal. Bioanal. Chem. 2019, 411, 6995-7003. [CrossRef] [PubMed]

44. Asefifeyzabadi, N.; Alkhaldi, R.; Qamar, A.Z.; Pater, A.A.; Patwardhan, M.; Gagnon, K.T.; Talapatra, S.; Shamsi, M.H. Labelfree Electrochemical Detection of CGG Repeats on Inkjet PrinTable 2D Layers of MoS2. ACS Appl. Mater. Interfaces 2020, 12, 52156-52165. [CrossRef] [PubMed]

45. Xu, S.; Zhan, J.; Man, B.; Jiang, S.; Yue, W.; Gao, S.; Guo, C.; Liu, H.; Li, Z.; Wang, J.; et al. Real-time reliable determination of binding kinetics of DNA hybridization using a multi-channel graphene biosensor. Nat. Commun. 2017, 8, 14902. [CrossRef]

46. Yang, I.V.; Thorp, H.H. Modification of Indium Tin Oxide Electrodes with Repeat Polynucleotides: Electrochemical Detection of Trinucleotide Repeat Expansion. Anal. Chem. 2001, 73, 5316-5322. [CrossRef] [PubMed]

47. Ge, Z.; Ma, M.; Chang, G.; Chen, M.; He, H.; Zhang, X.; Wang, S. A novel solution-gated graphene transistor biosensor for ultrasensitive detection of trinucleotide repeats. Analyst 2020, 145, 4795-4805. [CrossRef] 